\title{
A KIT OF APPS TO IMPROVE AND ASSESS EXECUTIVE FUNCTIONS AND WORKING MEMORY CAPACITY IN PRESCHOOLERS
}

\author{
Sabrina Panesi, Laura Freina and Lucia Ferlino \\ Institute for Educational Technology of the CNR, Via de Marini, 6, Genoa, Italy
}

\begin{abstract}
Several methods for the assessment and training of executive functions and working memory capacity in preschoolers have been developed over previous decades, but despite our digital era, new technologies are seldom addressed. To fill this gap, in the context of the "shareFUN" project, a set of digital games was designed, including measures and training activities for inhibition, shifting, updating and working memory capacity. The games were designed as a kit of apps since preschoolers show a deep interest and a high level of confidence in approaching digital games, mainly on tablets or smartphones. The current paper has the main aim to present this kit and outline further research activities, scheduled within the "shareFUN" project, for the validation of the apps used for assessment and their efficacy for training.
\end{abstract}

\section{KEYWORDS}

Executive Functions, Working Memory Capacity, Cognitive Training and Assessment, Preschoolers, App

\section{INTRODUCTION}

Executive Functions (EF) is an "umbrella term" that refers to a family of adaptive, goal-directed, top-down mental control processes. According to Miyake and colleagues (Miyake et al., 2000; Miyake and Friedman, 2012) the three core EF components are: inhibition, the ability to suppress task-irrelevant cognitive processing and ignore salient yet irrelevant features of the situation; shifting, the ability to switch between different operations or levels of processing; and updating, the ability to encode, hold and monitor incoming information in the working memory (WM), replacing the no longer relevant information with new one. Furthermore, these authors argued that these three core EF components rely to some extent on WM capacity, i.e. the simultaneous maintenance and manipulation of information. In line with this perspective, a recent study highlighted a strong relationship between inhibition, shifting, updating and WM capacity in preschoolers (Panesi and Morra, 2020): a period of most remarkable changes (Garon et al., 2008; Morra et al., 2018).

In preschool years, EF and WM capacity seem to be associated with and predictive of other domains as self-regulation (Sokol and Müller, 2007), social cognition (Denham et al., 2014), and future academic outcomes (De Franchis et al,, 2017), as well as behavioral problems (Allan and Lonigan, 2014) and ADHD symptoms (Pauli-Pott et al., 2014). Furthermore, EF deficits have been found in children with specific impairments or disabilities, such as preschoolers with autism (Pennington and Ozonoff, 1996), Down Syndrome (Lanfranchi et al., 2009), language impairment (Vissers et al., 2015), and also in children whose development is hampered by their low socio-economic backgrounds (Miech et al., 2001).

Due to the strong relationship between EF, WM capacity and other developmental domains in preschoolers, specific interventions to improve them at an early age, as well as appropriate tools for their assessment are crucial. Recently, Scionti and colleagues (2020) conducted a meta-analysis and found that cognitive training for preschoolers produced both near and far transfer effects, and that in this age range, a cognitive intervention has similar effects in younger and older children. They found positive effects of EF training programs in children both with and without developmental risks, in particular preschoolers with ADHD symptoms and with socially disadvantaged conditions. This finding suggests that cognitive interventions in an educational context enhancing the early development of some cognitive skills and 
resources, such as EF and WM capacity, may prevent future developmental risks. Finally, they found that cognitive EF training programs are more effective when done in a group, which calls for educational and clinical settings. However, in order to develop an effective cognitive intervention to foster EF and WM capacity, an accurate assessment of the child's developmental level is needed. Several methods of assessing EF and WM capacity in young children were developed over the last decades (Howard and Melhuish, 2017), nevertheless, there still are conceptual and pragmatic issues in early measurement of young children's emerging cognitive abilities. Actually, there is often a lack of clarity in the construct being measured, due to the difficulty of investigating EF and WM capacity in isolation; in fact, usually the tasks used measure also other cognitive processes, as visual or motor processes. This issue, known as "task impurity", is usually solved by administering multiple tasks, but, with preschoolers, one of the main problems is the lack of age-appropriate EF and WM capacity tasks. New digital technologies allow the introduction of new methods of assessment and intervention, however, to the best of our knowledge, there are only a few studies focused on technology based interventions promoting EF and WM capacity in preschoolers (Thorell et al., 2009), or assessing EF and WM capacity young children (Howard and Melhuish, 2017). Furthermore, they are usually developed for clinical purposes (Thorell et al., 2009).

This paper presents a new kit of apps for training and assessing of early EF and WM capacity development. Specifically, the kit includes assessment tasks and training activities of the three core EF components (i.e. inhibition, shifting, updating) and WM capacity for preschoolers.

\section{THE KIT OF APPS}

Within the "shareFUN" project"1, a tool for improving and measuring EF and WM capacity in preschoolers was designed in the form of a kit of apps (for details: Freina and Panesi, 2020). The aim was to create an easy to use tool, available for clinicians, researchers, but also for teachers and parents, allowing them to monitor and support young children's cognitive development in different contexts. Such a tool is very important especially when children cannot move from home, as was the case during the COVID-19 health emergency.

Today, young children start using digital games, mainly on tablets or smartphones, at a very young age. They generally show a deep interest in games and a high level of confidence in approaching the digital tools. In order to capture their attention and get the most from all session, four games were developed using the Unity 3D (https://unity.com/) development platform. Three games are aimed at one specific EF component, and the fourth at WM capacity (see Table 1). Each was developed as a separate app, for a tablet or smartphone with a touch interface.

Table 1. The kit of apps for Android to measure and improve EF and WM capacity

\begin{tabular}{ccc}
\hline App & Refers to \\
Basilio & Inhibition \\
The Farmer Magic House & & \\
Evelyn & &
\end{tabular}

\footnotetext{
1 "shareFUN" (https://www.sharefun.it) is a project of the Institute for Educational Technology of the Italian National Research Council (ITD-CNR), co-funded by the Operative Program POR FSE Liguria Region 2014-2020 Code: RLOF18ASSRIC/77/1.
} 
Each game can be used as a test or training tool: in test mode, the game goes through a fixed sequence of tasks, while all the actions of the player are logged on a cloud database for later analysis. All the logged data is anonymous, children are identified with a code and the association between the code and the single child is external to the games. Furthermore, no feedback is given, and when the error rate gets higher than a threshold, the game finishes. When the games are used for training purposes, data from the game is not logged and a specific feedback is provided to correct errors and help the child reflect about his own performance.

All the games are designed to be used directly by the child under supervision of an adult. Instructions are spoken to make them accessible to the child, while, short written messages remind the adult about the task.

Basilio (inhibition). Basilio is a nice little ghost who invites the child to try to touch him. At first, only reaction times are logged, but later Basilio presents some friends of his and asks the player to touch him as quicky as possible, but to avoid touching the other characters. Then, one character appears on the screen for one second and the child has to touch it only if it is Basilio, while avoiding all the other characters.

The Farmer (shifting). In the game, a farmer presents his eight baby animals: a lamb, a chick, a kitten and a puppy with their mothers. Four animals are white and four are colored. On the scene there are a large white house and a little red one. The game asks the child to touch the house where each animal should go, using two different classification rules:

- Mother/baby: when the farmer is on site, babies go to the little house and mothers to the large one;

- White/colored: when the farmer is out of sight, white animals go to the white house, and colored animals to the red one.

After a set of trials where the two rules are presented separately, the child has to decide which rule to use depending on the presence of the farmer: when present, the mother/baby rule should be used, otherwise the color rule should be used.

The Magic House (updating). Eight little animals, after presenting themselves, want to play together in a little house, but the house is magic, and only the last two animals that enter the house can play together. A sequence of 3 to 6 animals entering the house one after the other is shown and then the child has to touch the last one that entered the house, and then the second-last one (Panesi and Morra, 2017).

Evelyn (WM capacity). Evelyn, a young puppy, challenges the child to remember a sequence of everyday objects. The objects are shown one at a time, and then the child is asked to touch the objects s/he has seen. At the beginning, the child can touch them in any order, later the objects have to be touched in the same order as they have been shown, and finally, (to test the WM capacity) they have to be touched in an inverse order, starting from the last one.

\section{CONCLUSION AND FURTHER RESEARCH}

In this paper we described a kit of apps developed for assessing and training EF and WM capacity in preschoolers. The apps, including tests and training activities, can be easily used by clinicians, teachers, families, and researchers. Moreover, the small games in the form of apps for tablets are easy to use and motivating for preschoolers.

All the apps were ready for a first evaluation from the end users in spring 2020, but, due to the lockdown caused by COVID-19, all schools, including nursery schools, were closed and it was not possible to get in touch with the children. At present, schools have just reopened, and lots of measures are in place to guarantee students' safety, it is therefore impossible to organize a wide scale validation.

In the next months, two different research actions are planned:

ACTION 1: (i) some professionals (clinicians, teachers and researchers) will test the four apps while filling in a questionnaire. After their test, a focus group will be organized to discuss their opinions and collect suggestions for further refinements; (ii) a limited set of children of the target age will be involved in playing with the game. All children will use the games in a supervised manner, involving directly the researchers. While children will be playing, a structured interview will be carried out and observations will be made in order to evaluate the ease of use and the child's appreciation. 
ACTION 2: (i) a much wider validation of the apps in the test mode will be organized, administering the kit of apps and a battery of traditional tests to measure EF and WM capacity to a large sample of preschoolers; (ii) the efficacy of the training activities with the apps will be investigated by administering a battery of traditional tests to measure EF and WM capacity as pre- and post- test to a sample of preschoolers that will use the games for training (experimental group) and to another sample of preschoolers that will continue traditional activities (control group) in the educational context.

The kit of apps will be tested with children with typical development and with some young children with atypical development in the clinical context.

\section{REFERENCES}

Allan, N. Lonigan, C., 2014. Exploring dimensionality of effortful control using hot and cool tasks in a sample of preschool children. Journal of Experimental Child Psychology, Vol. 122, pp. 33-47.

De Franchis, V., Usai, M.C.,. Viterbori, P., Traverso, L., 2017, Preschool executive functioning and literacy achievement in Grades 1 and 3 of primary school: A longitudinal study. Learning and Individual Differences, Vol. 54, pp. 184-195

Denham, S.A., Bassett, H.H., Zinsser, K., Wyatt, T.M., 2014. How preschoolers' social-emotional learning predicts their early school success: Developing theory-promoting, competency-based assessments. Infant and Child Development, Vol 23, No. 4, pp. 426-454.

Freina, L., Panesi, S. (2020). ShareFUN project: Executive functions in pre-schoolers. CNR-ITD Internal Report. Available online at: http://bit.ly/IntRepPanesi .

Garon, N., Bryson, S. E., \& Smith, I. M., 2008. Executive function in preschoolers: A review using an integrative framework. Psychological Bulletin, Vol. 134, No.1, pp. 31-60.

Howard, S. J., \& Melhuish, E., 2017. An early years toolbox for assessing early executive function, language, self-regulation, and social development: Validity, reliability, and preliminary norms. Journal of Psychoeducational Assessment, Vol. 35, No. 3, pp. 255-275.

Lanfranchi, S., Jerman, O. Vianello, R., 2009. Working memory and cognitive skills in individuals with Down syndrome. Child Neuropsychology, Vol.15, No. 4, pp. 397-416.

Miech, R., Essex, M., Goldsmith, H.H., 2001. Socioeconomic status and the adjustment to school: The role of self-regulation during early childhood. Sociology of education, pp. 102-120.

Miyake, A., \& Friedman, N. P. , 2012. The nature and organization of individual differences in executive functions: four general conclusions. Current Directions in Psychological Science, Vol.21, No.1, pp. 8-14.

Miyake, A., Friedman, N. P., Emerson, M.J., Witzki, A.H., Howerter A., \& Wager, T.D., 2000. The unity and diversity of executive functions and their contributions to complex "Frontal Lobe" tasks: a latent variable analysis. Cognitive Psychology, Vol.41, No. 1, pp. 49-100.

Morra, S., Panesi, S., Traverso, L., \& Usai, M. C., 2018. Which tasks measure what? Reflections on executive function development and a commentary on Podjarny, Kamawar, and Andrews (2017). Journal of Experimental Child Psychology. Vol. 167, pp. 246-258.

Panesi, S., \& Morra, S., 2020. Executive functions and mental attentional capacity in preschoolers. Journal of Cognition and Development, Vol.21, No.1, pp. 72-91.

Panesi, S., Morra, S., 2017. La casetta magica. Uno strumento per indagare l'aggiornamento (updating) della memoria di lavoro in età prescolare [The magic house. A new measure of updating for preschoolers]. Psicologia Clinica dello Sviluppo, Vol. 21, No .3, pp. 443-462.

Pauli-Pott, U., Dalir, S., Mingebach, T., Roller, A., \& Becker, K., 2014. Attention deficit/hyperactivity and comorbid symptoms in preschoolers: Differences between subgroups in neuropsychological basic deficits. Child Neuropsychology, Vol. 20, No. 2, pp. 230-244.

Pennington, B.F., Ozonoff S., 1996. Executive functions and developmental psychopathology. Journal of child psychology and psychiatry, Vol. 37, No.1, pp. 51-87.

Scionti, N., Cavallero, M., Zogmaister, C., \& Marzocchi, G. M., 2020. Is cognitive training effective for improving executive functions in preschoolers? A systematic review and meta-analysis. Frontiers in Psychology, 10, 2812.

Sokol, B.W., \& Müller, U., 2007. The development of self-regulation: Toward the integration of cognition and emotion. [Editorial], Cognitive Development, Vol. 22, No. 4, pp. 401-405.

Thorell, L.B., Lindqvist, S. Bergman Nutley, S., Bohlin, G., \& Klingberg, T., 2009. Training and transfer effects of executive functions in preschool children. Developmental science, Vol. 12, No. 1, pp. 106-113.

Vissers, C., Koolen, S., Hermans, D., Scheper, A., Knoors, H., 2015. Executive functioning in preschoolers with specific language impairment. Frontiers in psychology, 6:1574. 